\title{
A emergência complexa nas interações de um grupo de professores em formação em ambiente virtual
}

Luciana de Oliveira SILVA ${ }^{1}$

\footnotetext{
${ }^{1}$ Universidade Federal de Minas Gerais (UFMG), luciana.fale@gmail.com, orcid. org/0000-0001-8109-2389.
} 
RESUMO O presente artigo, recorte de uma pesquisa de doutorado, investiga o uso do ambiente virtual de aprendizagem (AVA) como espaço de interação e colaboração para professores em formação. Seu propósito é apontar quais indícios das condições para emergência complexa propostas por Davis e Simmt (2003) e Davis e Sumara (2006) existem nas interações ocorridas. A perspectiva da Complexidade é adotada para a análise dos dados. O estudo constituiu-se de uma pesquisa de natureza qualitativa e de orientação etnográfica virtual (HINE, 2000). Os dados revelam que as condições para emergência complexa foram observadas no grupo investigado e se apresentam de forma interrelacionada, contribuindo para que o sistema se mantenha estável, coerente e equilibrado.

ABSTRACT This article, a fragment of a doctoral research, investigates the use of virtual learning environment (VLE) as a space for interaction and collaboration for teachers in training and aims at pointing out which evidence of the conditions for complex emergency, proposed by Davis and Simmt (2003) and Davis and Sumara (2006), exist in the interactions. The complexity perspective is adopted for data analysis. The study has characteristics of a qualitative research and virtual ethnography (HINE, 2000). The 
data shows that the conditions for complex emergency were observed in the investigated group, in an interrelated way, contributing to stability, coherence and balance of the system.

PALAVRAS-CHAVE ambientes virtuais. emergência complexa. etnografia virtual. formação de professores.

KEYWORDS virtual environment. complex emergence. virtual ethnography. teacher education 


\section{Introdução}

A formação do professor no Brasil, de maneira geral, tem raízes em tradições filosóficas e paradigmas coerentes com o momento político e ideológico (MARTINS, 2007). Políticas macroeconômicas regem as reformas do ensino superior em geral (CARVALHO, 2006) e conduzem a legislação dos cursos de licenciatura, trazendo mudanças que culminam, muitas vezes, em perdas irreparáveis. A grande maioria dos cursos de formação, segundo Barreto (2011), tem uma predominância de disciplinas das áreas de referência (as disciplinas específicas do curso, como Língua Portuguesa, Latim e Literatura no curso de Letras) sobre aquelas voltadas para a discussão das práticas educacionais. Disciplinas de referência e de formação pedagógica não se relacionam e dialogam nos ementários e noções dos sistemas educacionais são pouco expressivas. A estrutura curricular, segundo Barretto (2011), não contempla, de forma pertinente, gestão escolar, currículos e o trabalho docente.

Nota-se, também, uma falta de base pedagógica em relação ao Estágio Curricular Supervisionado (ECS), com número de horas incompatíveis com as demandas de formação e vivência escolar exigidas para um professor qualificado. Esse momento do ECS é decisivo na formação, pois o aprendiz de professor se prepara para atuar em um espaço que, embora não lhe seja totalmente estranho, apresenta-se como novo em relação às tomadas de decisões profissionais que esse aprendiz terá que empreender.

Na primeira metade da década de 2000 , cursos de licenciatura a distância pelas universidades públicas, especialmente as federais, foram incentivados pelo Ministério da Educação, sob sua direta jurisdição (BARRETTO, 2011). O Programa Pró-Licenciatura foi criado em 2005 e A Universidade Aberta no Brasil ${ }^{2}$ - UAB - tornouse realidade em 2006 , com o objetivo de promover a formação inicial

${ }^{2}$ Disponível em: http://www.uab.capes.gov.br/index.php. 
e continuada de professores da educação básica com metodologia à distância. Esse movimento garantiu o acesso de professores em formação a ambientes virtuais de aprendizagem (AVAs), com uso de ferramentas digitais e "vivências" de uma nova forma de ensino e aprendizagem. Não se sabe, no entanto, se nesse ambiente considerado inovador, as práticas pedagógicas eram consoantes com esta inovação.

Um AVA é, de acordo com Dillenbourg et al. (2002), um espaço social de informação, explicitamente representado por elementos que variam de textos a mundos imersivos de terceira dimensão. Ele não é restrito à Educação a Distância - EaD - e integra tecnologias homogêneas e variadas abordagens pedagógicas. A partir da junção "cursos de licenciatura + AVAs", novas possibilidades na formação de professores são vislumbradas na esfera educacional, mesmos para cursos que ainda são realizados de forma totalmente presencial. Uma delas é o uso do espaço on-line para um diálogo reflexivo entre professores em formação e professores formadores. É possível encontrar, nesta modalidade de aprendizagem reflexiva, formas alternativas para que a fragmentação da estrutura de prática docente nas licenciaturas seja reduzida. Há, ainda, a possibilidade de experiências comunicadas em um grupo de colaboração didática online, que possa consolidar a formação do futuro professor.

Vale destacar dois importantes motivos para uma integração do virtual com o ECS. Um deles é o perfil dos "alunos digitais" que professores em formação encontrarão em suas salas de aula. O outro motivo é a possibilidade, a partir da proposta da constituição de um novo paradigma de ECS, de envolver professores aprendizes em ambientes virtuais, criando uma rede digital de reflexão, interação e colaboração entre esses atores escolares para que eles possam experimentar uma supervisão em rede, com pressupostos baseados na interação e colaboração, e uma experimentação dos novos papéis que professores e aprendizes podem assumir em um contexto de formação à distância. 
O mundo virtual, nesse contexto, funciona como um campo on-line de experiências, propiciando oportunidade de feedback coletivo a um grupo de professores em formação, de forma que um estágio colaborativo possa ser realizado com a troca de experiências coletivas. Essa forma de possibilidade para o estágio supervisionado, traz à tona desafios que os professores em formação encontram nas salas de aulas, fazendo com que uma reflexão em conjunto seja estimulada.

Acredita-se que o espaço virtual projetado para as discussões do estágio curricular e das práticas de ensino, mais do que um simples espaço de relatos, é um espaço dinâmico de participação ampla e situada, que propicia a criação de diários reflexivos repletos de experiências significativas. Esse espaço virtual deixa legados para futuros professores em formação, além de ser um espaço apropriado para que esses professores possam desenvolver sua competência tecnológica.

Tal dinamicidade torna possível perceber esse ambiente virtual como um sistema complexo no qual interações entre diferentes elementos podem fazer emergir eventos ou ações resultantes da coletividade estabelecida nos grupos de aprendizagem. Esses eventos emergentes, que surgem das relações e interações que acontecem no sistema e que regem o seu comportamento, não podem ser provocados, simplesmente, segundo Davis e Simmt (2003) e Davis e Sumara (2006). Eles podem ser motivados por certas condições apropriadas que encontramos no ambiente investigado.

Assim considera-se necessária a proposição de novas possibilidades paraoECS, paraque ele searticule deformaapromover experiências comunicadas dentro do ambiente escolar, com maior participação do professor orientador e a presença de conteúdos relativos ao uso dos recursos tecnológicos e informacionais, ponto ressaltado nas diretrizes estabelecidas para as licenciaturas. 
O estudo que gerou esse artigo surgiu de inquietações a partir do trabalho da autora como professora da Educação Básica (por 10 anos) inserida em um locus de formação (uma escola de aplicação dentro de uma universidade federal), responsável por orientação de ECS. Ele buscou envolver o professor em formação em um AVA que contemplasse tanto a prática quanto a reflexão sobre essa prática. Esse artigo objetiva apontar quais indícios das condições para emergência complexa propostas por Davis e Simmt (2003) e Davis e Sumara (2006) existem nas interações entre professores em formação em ambiente virtual de aprendizagem considerado um sistema complexo.

\section{O paradigma da complexidade}

O vocábulo "complexidade" sugere algo entrelaçado, tecido juntamente ou compreendendo diversos elementos, um termo surgido no início do século XX na psicanálise, na psicologia e na medicina. Ele veio à tona quando pesquisadores dessas diversas áreas perceberam, em seus estudos, que havia mais do que uma estrutura puramente linear nas relações diversas.

O adjetivo complexo é muitas vezes confundido com "complicado", de difícil entendimento, que Cilliers (1998) explica: "complicado" é o que pode consistir em um grande número de componentes e que pode ter uma descrição completa em termos de seus constituintes individuais. Já o termo "complexo", segundo o mesmo autor, se refere à interação entre os constituintes do sistema e a interação entre o sistema e seu meio são de tal natureza que o sistema não pode ser totalmente compreendido simplesmente pela análise de seus componentes. Assim, sistemas que são considerados complexos apresentam uma constituição específica de interação, explicitada na próxima seção. 


\subsection{Sistemas adaptativos complexos}

Sistema, do grego synhistanai (colocar junto), é definido por Bertalanffy (1975) como um conjunto de elementos em interação. Entender as situações de forma sistêmica significa, segundo Capra (1996) contextualizá-las e relacioná-las dentro de sua natureza dinâmica. Larsen-Freeman e Cameron aprofundam-se neste conceito ao dizer que "um sistema é produzido por um conjunto de componentes que interagem de formas específicas para produzir uma forma ou estado geral em um ponto específico no tempo" (LARSEN-FREEMAN; CAMERON, 2008, p. 26).

Há dois diferentes tipos de sistemas, segundo Bertalanffy (2008), os fechados e os abertos. Sistemasfechados são consideradosisolados de seu ambiente e não mantêm intercâmbio algum com o meio em que estão localizados. Um relógio é um exemplo de sistema fechado. Os sistemas abertos, segundo o mesmo autor, estão em interação com o meio e podem tanto influenciá-lo quanto serem influenciados por ele. Todo organismo vivo é essencialmente um sistema aberto, segundo Bertalanffy (2008).

Os sistemas complexos apresentam a dinamicidade com característica essencial. Em um sistema complexo dinâmico, os agentes mudam com o tempo, levando o sistema a mudanças e promovendo mais alterações a cada interação subsequente dos mesmosagentes (LARSEN-FREEMAN;CAMERON,2008).Mudança e heterogeneidade são pontos centrais à Teoria da Complexidade (LARSEN-FREEMAN, 2007). Essas autoras salientam que essa teoria é representada por um movimento de estabilidade temporária, por meio de comportamentos adaptativos, que fazem emergir novos padrões, em diferentes níveis e escalas de tempo ${ }^{3}$, que não podem ser explicados pelas ideias reducionistas e cartesianas.

${ }^{3}$ Ver essa discussão em Larsen-Freeman e Cameron (2008). 
A estrutura de um sistema sofre alterações a partir das mudanças (suaves/contínuas ou abruptas/radicais) pelas quais ele passa e um estado de turbulência pode surgir desse comportamento, segundo Larsen-Freeman e Cameron (2008). As autoras ressaltam que as mudanças radicais geram uma condição qualitativamente diferente da anterior, e o sistema atinge uma bifurcação.

Já as mudanças suaves ou bruscas, que acontecem durante a trajetória desse sistema, compõem o que Larsen-Freeman e Cameron (2008) chamam de "estados do sistema". A cada mudança de estado acontece uma mudança no padrão de comportamento. Ao longo da trajetória do sistema, ele tende a preferir um caminho ou um padrão mais específico e a essa preferência dá-se o nome de estado atrator (LARSEN-FREEMAN; CAMERON, 2008). Essa condição, segundo Kauffman (1993), leva o sistema a uma auto-organização. Na próxima seção há um detalhamento maior desta auto-organização e dos elementos que a compõem.

\subsection{Auto-organização e emergência}

De acordo com Kelso (1995), formações espontâneas de padrões são o que se pode chamar de auto-organização. Pallazzo (1999) afirma que há uma organização espontânea a partir da desordem, que parece ser dirigida por leis físicas que não conhecemos. Essa ordem surge, de alguma maneira, a partir das múltiplas interações entre os agentes desse sistema.

A auto-organização faz surgir um nível diferente do sistema, num processo chamado emergência. Segundo Larsen-Freeman e Cameron (2008), o que surge a partir da mudança de fase é um todo maior do que a soma das partes, que não pode ser explicado pela simples análise de cada parte isoladamente. O comportamento emergente tem uma totalidade reconhecida e, segundo Holland (1998), tem padrões persistentes com componentes em mudança. 
Em um contexto educacional, numa relação dinâmica em que aprendizes interagem com a escola, com os professores, com o sistema de ensino e com os próprios aprendizes, os fenômenos emergentes representam uma associação de fatores que ultrapassa a soma de cada uma dessas partes. As interações de aprendizagem, as práticas decorrentes dessas interações e os resultados que elas trazem na vida de cada sujeito envolvido fazem surgir uma nova configuração no sistema. O conhecimento, segundo Osberg, Biesta e Cilliers (2008), emerge das nossas transações com o ambiente e retroalimenta esse mesmo ambiente, de forma que ele passa a ser extremamente significativo para nós. $\mathrm{O}$ aprendiz não é observador, mas sim atuante, em uma dinâmica na qual o conhecimento chega até nós não como algo que recebemos, mas como uma resposta às nossas ações (OSBERG; BIESTA; CILLIERS, 2008).

As interações no espaço da aula, seja ela presencial ou virtual, provocam eventos que, como já mencionado anteriormente, não surgem aleatoriamente. Eles são motivados por condições apropriadas que são encontradas no ambiente investigado, que são abordadas na próxima seção.

\section{Condições para a emergência complexa}

São seis as condições consideradas adequadas por Davis e Simmt (2003) e Davis e Sumara (2006) para que eventos emergentes sejam possíveis: diversidade interna, redundância, interação entre os vizinhos, controle descentralizado, coerência e aleatoriedade. Johnson (2001) salienta que essas condições fazem parte de uma lista maior, sujeita a constantes revisões.

A diversidade interna, segundo Davis e Simmt (2003) e Davis e Sumara (2006), considera a heterogeneidade presente em grupos sociais, analisando as diferenças existentes dentro do sistema. 
Essa condição é entendida como uma fonte de possíveis respostas a circunstâncias emergentes e define o alcance dessas possíveis respostas.

A redundância é o complemento da diversidade, uma condição necessária para que haja a atividade cooperativa e que permite ao sistema lidar com o stress ou com uma mudança súbita. Ela possibilita a interação entre os agentes e, quando necessário, permite que eles compensem falhas que trazem consigo, uma vez que ela se refere às semelhanças encontradas dentrodogrupo (comoalíngua em comum, o status social semelhante, as responsabilidades compartilhadas, dentre outros exemplos).

Essas duas condições devem estar equilibradas dentro do sistema, uma vez que elas são fontes de estabilidade e criatividade: menos redundância faz com que o sistema perca a robustez e tenha dificuldades de adaptação em seu contexto; por outro lado, menos diversidade leva o sistema à capacidade reduzida de responder aos eventos de maneira precisa e inteligente, uma vez que respostas diversas estarão em falta, e essas perturbações podem causar um colapso do sistema (DAVIS; SIMMT, 2003; DAVIS; SUMARA, 2006).

A terceira condição apontada é a interação entre os vizinhos. "Vizinhos", nesse caso, em um contexto educacional (Davis e Simmt (2003) e Davis e Sumara (2006)), são as ideias, intuições, questionamentos e outras representações. Isso não exclui o componentefísicoeopapeldainteraçãosocial.Paraospesquisadores, as ideias devem se encontrar em espaços diversos como seminários, congressos e trocas mediadas pelo texto para que elas sejam combinadas e aperfeiçoadas para gerar insights, projetos e conceitos que constituem o corpo de conhecimento do grupo, gerandoum saber coletivo em vez de promover apenas uma coletividade interpessoal. 
Para que a interação entre os vizinhos seja possível, os membros do grupo devem trabalhar com a ideia de responsabilidade distribuída. Por isso, segundo Davis e Simmt (2003) e Davis e Sumara (2006), o controle descentralizado é mais uma condição importante para eventos emergentes, já que impor uma autoridade única significaria extinguir o potencial emergente desse conhecimento. Os autores chamam atenção para a ênfase dada aos vizinhos como as "representações", para lembrar que essa referência ao controle não diz respeito às responsabilidades dos professores, do currículo e da organização escolar.

A coerência e a aleatoriedade são condições complementares. Para entender a primeira, é necessário lembrar que sistemas sociais são definidos por regras, que existem para que haja um limite nas atitudes dos agentes. Essa delimitação serve para trazer coerência ao comportamento do grupo, mas ao mesmo tempo ela abre um espaço ilimitado de possibilidades (em relação ao que se pode ser feito), que podem ser interpretadas como a aleatoriedade (DAVIS; SUMARA, 2006). Essas condições oferecem um equilíbrio ao sistema porque há coerência suficiente nas ações dos agentes e ao mesmo tempo permite-se uma resposta variada e flexível. Nesse caso, segundo os autores, não há o risco de "todos fazerem a mesma coisa" ou "cada um fazer o que quer do seu jeito"; o resultado final é "todos participam de um projeto conjunto" (DAVIS; SUMARA, 2006, p. 149).

Em um curso realizado em um AVA, normas determinadas para o bom andamento do processo podem funcionar como coerência, favorecendo ou não a aleatoriedade. Algumas regras de funcionamento de um curso são bem restritas e, por vezes, fecham possibilidades de ação, uma vez que devem ser consideradas dentro do contexto específico da escola.

A partir do exposto, os AVAs são apresentados na seção seguinte, de forma que suas características e possibilidades sejam explicitadas. 


\section{Ambientes Virtuais de Aprendizagem - AVAs}

Dillenbourg et al. (2002) e Santos (2005) afirmam que um Ambiente Virtual de Aprendizagem pode se justapor a um espaço físico ao agregar ferramentas desse espaço, eliminando fronteiras. Esses espaços são favoráveis à formação de comunidades, permeadas por hábitos culturais, histórias, regras, leis e procedimentos, permitindo a que os agentes, neste caso alunos e professor, interajam de forma consciente.

Diversos AVAs, ou plataformas virtuais, já são bem conhecidos no ciberespaço, alguns gratuitos, alguns com custos e formatos que variam de acordo com a necessidade do cliente. Dentre eles, cita-se o AulaNet, da PUC-RJ (Brasil), o Blackboard, da empresa de mesmo nome (EUA), o Learning Space, do Lotus Education - Institute IBM (EUA), o TELEDUC, da Unicamp NIEED (Brasil) e o WebCT, da University British, Columbia (Canadá). Merecem atenção, também, o MOODLE, acrônimo de Modular Object-Oriented Dynamic Learning Environment, o Dokeos, um software pago de uma empresa de Massachusets, e o iTutor, da empresa Kontis (Brasil). Dentre todos eles, destaca-se o TELEDUC, a plataforma escolhida para a investigação proposta neste trabalho.

Aaprendizagem noambientevirtual, levando-se em consideração aspectos interacionais, estratégicos, avaliativos e discursivos, tem sido objeto de investigação consistente, tanto no Brasil quanto no exterior. Já em 1992, Pea e Gomez (1992) analisavam as possibilidades da criação de ambientes de aprendizagem distribuída no meio virtual, e teciam considerações sobre o ensino transmissivo e o ensino transformador. O trabalho desses autores já apresenta como escopo teórico o "aprender fazendo" (DEWEY, 1956 apud por PEA; GOMEZ, 1992), bem como o aspecto situacional da aprendizagem em comunidades de prática, com base em Lave e Wenger (1990) 
e outros autores, e ainda a negociação de sentido com subsídios da Análise Conversacional (SCHEGLOFF; SACKS, 1973 apud por PEA; GOMEZ, 1992).

Importante ressaltar que, nesta pesquisa, os autores enfatizam o ambiente educacional como foco do trabalho, e não outros segmentos sociais (museus, bibliotecas, centros comunitários, etc.), porque já se vislumbrava o impacto positivo da tecnologia online nas práticas de ensino e aprendizagem, mas também já se previa que, sem um desenho apropriado dos ambientes educacionais e das ferramentas neles contidas, esse impacto seria bastante reduzido.

\subsection{Estruturas dos AVAs}

Ambientes virtuais de aprendizagem são concebidos a partir de pressupostos teóricos que expressam as ideias sobre ensino e aprendizagem que os compõem. Eles são, segundo Hannafin et al. (1997) e Land e Hannafin (2000), espaços bem-sucedidos de construção e co-construção do conhecimento, e devem estar alicerçados em cinco dimensões e suposições centrais para que sejam reconhecidos como espaços bem-sucedidos de construção e co-construção de conhecimento (considerados aqui ambientes construtivistas): psicológica, pedagógica, tecnológica, cultural e pragmática.

A dimensão psicológica enfatiza pressupostos teóricos sobre como os indivíduos pensam e aprendem e a pedagógica está relacionada ao que o indivíduo é capaz de fazer e às atividades do ambiente. A segunda está, segundo Hannafin et al. (1997) e Land e Hannafin (2000), intimamente relacionada à primeira, uma vez que estratégias pedagógicas são consistentes com suposições de natureza psicológica. A dimensão tecnológica influencia a forma como as mídias podem oferecer apoio ao ambiente, levando em consideração a base epistemológica desse ambiente. Essa dimensão, segundo eles, 
pode ser percebida no design da plataforma utilizada para a disciplina e nas ferramentas propostas para o desenvolvimento do curso.

A dimensão cultural, segundo Hannafin et al. (1997) e Land e Hannafin (2000), reflete os valores de aprendizagem de uma comunidade de aprendizagem, podendo reproduzir valores como "aprendizagem interdisciplinar" ou "aprendizagem global". Por fim, a dimensão pragmática enfatiza o uso de recursos e o uso real de qualquer ambiente, avaliando a validade do desenho e da implementação desse ambiente, constantemente reavaliando o alinhamento entre as outras dimensões.

Na criação de um AVA, o aprendiz deve ser conduzido ao centro do processo de aprendizagem, considerando o engajamento do aluno em atividades dinâmicas e ligadas à sua realidade (CLARK; MAHER, 2001). Dessa forma, não podemos desconsiderar o contexto no qual a atividade ${ }^{4}$ acontece, e esse contexto deve ser avaliado e compreendido para uma melhor análise do processo da aprendizagem (DUFFY; CUNNINGHAM, 1996).

Diante do exposto, percebe-se que o ambiente virtual deve ser estruturado de modo a permitir que eventos de aprendizagem aconteçam de forma espontânea e integrada. Sendo assim, é impossível pensar esta pesquisa sem a perspectiva da Teoria da Complexidade, que abarca as ações, interações e relações entre os agentes que compõem o sistema intricado de possibilidades emergentes, que é a educação.

A próxima seção é dedicada aos procedimentos metodológicos da pesquisa, com explicitação de seu contexto e seus personagens.

${ }^{4}$ Atividade, neste trabalho, refere-se às interações ocorridas no ambiente, as "trajetórias de ações que tendem a se manter, a menos que algo aconteça para mudá-las" (GREENO, 1998, p.13). 


\section{Metodologia}

Esta pesquisa é de natureza qualitativa e tem o pesquisador envolvido em uma experiência intensiva com os participantes. Ela busca compreender o fenômeno em um contexto específico e se justifica na afirmação de Strauss e Corbin (1990) de que a pesquisa qualitativa deve ser usada para se entender um fenômeno sobre o qual pouco se sabe. Nesse caso, o fenômeno é a interação de professores em formação em um ambiente virtual, ao longo de um semestre letivo.

Nas características da pesquisa qualitativa, apontadas por Bogdan e Biklen (1982); Lincoln e Guba (1985) e Patton (1990), uso do ambiente como fonte de dados, o foco nos processos emergentes da pesquisa e o posicionamento do pesquisador como instrumento humano de coleta de dados são destacados. Essas características não são, segundo Patton (1990), incontestáveis. Elas servem de base para apontar uma direção para a forma mais adequada de coleta de dados.

A perspectiva etnográfica também está presente neste estudo. Essa escolha se deu porque primeiramente há um envolvimento na "vida" de um grupo por um período de tempo, observando o que acontece e o que é dito no ambiente onde as interações do grupo ocorrem, e questionando informações que vão se transformar em dados (HAMMERSLEY; ATKINSON, 1995). Em segundo lugar, porque esta pesquisa é vista sob o paradigma da complexidade, concebendo o espaço de interações como um sistema dinâmico e auto organizável, que também interage com outros ambientes e sistemas (KUHN; WOOG, 2005).

A investigação está inserida em um contexto sem limites reais e concretos e sem fronteiras nas interações e trocas, como ressalta Hine (2000), o que o caracteriza como um sistema adaptativo complexo. Esse contexto, a Internet, é basicamente "uma maneira de transmitir bits de informação de um computador para outro", segundo a mesma autora, mas que detém uma vida social e discursiva 
autêntica e interativa. A Internet é um "artefato cultural moldado por processos sociais na produção e no uso" (HINE, 2000, p.39) e não se instala como um espaço físico, mas se organiza em torno de uma conexão e por isso transforma o conceito de deslocamento que a etnografia traz embutido em si.

Hine (2000, p. 42) ressalta que a etnografia "oferece a promessa de se aproximar da compreensão de como as pessoas interpretam o mundo e organizam suas vidas". A autora enfatiza que por meio dessa abordagem de pesquisaé possível compreender uma cultura combase nos conceitos que emergem do estudo realizado. A etnografia virtual, segundo ela, detalha maneiras nas quais a tecnologia é vivenciada e experimentada.

Vale ressaltar quea potencialidade de arquivamentoquea Internet oferece é um ponto positivo para um pesquisador: ele tem a chance de voltar aos registros sempre que precisar. Mendes (2009), citado por Silva (2013), atenta para o fato de que a coleta de dados na pesquisa em um ambiente online oferece ao pesquisador a possibilidade de acompanhar o andamento da pesquisa à medida que os dados surgem no ambiente, fazendo alterações no curso da investigação.

Hine (2000) chama a atenção para a exposição de dados no meio virtual. Em um meio on-line aberto, não protegido por uma senha de acesso, os dados reais, como nomes, datas e informações diversas ficam acessíveis a qualquer um que queira esse acesso. $\mathrm{O}$ anonimato do informante na web é, portanto, impossível neste caso. A solução, segundo a autora, está na necessidade de o pesquisador aplicar uma sensibilidade etnográfica aos problemas éticos em potencial. No caso desta pesquisa, $\mathrm{o}$ ambiente era restrito à professora pesquisadora $\mathrm{e}$ aos professores em formação que participaram do trabalho. Assim, $o$ anonimato foi mantido. 
A pesquisa foi desenvolvida na Faculdade de Letras - FALE da Universidade Federal de Minas Gerais - UFMG, com oferta de uma disciplina totalmente on-line, intitulada "O uso de tecnologias digitais no ensino de Língua Inglesa” no primeiro semestre de 2011, com carga horária de 60 horas, organizada em 15 semanas com 4 horas semanais de aula. Dos treze alunos que concluíram totalmente a disciplina, dez alunos permitiram o uso de dados produzidos por eles nesta pesquisa.

Oferecida no ambiente TELEDUC, o tema da disciplina contemplava ferramentas e práticas pedagógicas em ambiente virtual e tinha como requisito básico a realização de um estágio presencial colaborativo em uma escola de Ensino Fundamental. A disciplina tinha como objetivo o desenvolvimento da competência tecnológica do professor em formação e a promoção de uma oportunidade de prática reflexiva, com uso das ferramentas tecnológicas trabalhadas na disciplina. Ao final do semestre, os alunos responderam a um questionário por e-mail, que serviu de base para uma entrevista não estruturada realizada posteriormente. A entrevista foi gravada em áudio e integralmente transcrita.

O primeiro passo para a análise foi a seleção dos dados que contribuíram para a investigação proposta, a partir do objetivo da pesquisa. Após a organização sequencial das mensagens do fórum de discussões, das notas de campo, dos documentos referentes à disciplina (plano de curso, cronogramas de atividades, etc.), da transcrição das entrevistas, foi feita a impressão e agrupamento do material de acordo com o instrumento utilizado para a coleta.

A partir de palavras-chave e anotações pertinentes ao material, foi feito um processo de codificação com base nas questões que guiaram este estudo. Esses dados foram categorizados para a busca de padrões e aspectos relevantes e agrupados dentro dos seus respectivos temas. 


\section{Análise e discussão dos dados}

Esta análise considera o ambiente virtual como uma rede de agentes e componentes que agem e interagem em uma dinâmica aleatória. Por meio do comportamento dessa rede de agentes e componentes foi possível reconhecer e contextualizar, nesse ambiente, as características inerentes a um sistema complexo, tais como a imprevisibilidade, a turbulência, a dinamicidade, a não-linearidade, a diversidade, seu múltiplo nível de organização e sua capacidade de prever o futuro através dos modelos internos. Apesar desse reconhecimento, analisar esse ambiente como um sistema complexo não é o objetivo deste trabalho, uma vez que isso já foi investigado e aprofundado por outros pesquisadores (PARREIRAS, 2005; BRAGA, 2007; MARTINS, 2008).

Esta seção apresenta evidências de que o AVA é um espaço em que é possível emergir atitudes, comportamentos e crenças diversas, a partir das interações ocorridas. Para sustentar essa constatação, a autora aponta indícios das condições necessárias a um ambiente para a emergência de eventos complexos presentes nesse ambiente. Ela recorre às interações entre professores em formação no AVA para apontar a diversidade interna e a redundância do sistema, o controle descentralizado ali estabelecido, as interações locais/entre vizinhos e as restrições possibilitadoras. Por meio de excertos, ela descortina ao leitor eventos que ilustram as condições que nos permitem compreender a natureza do sistema ora investigado 5 .

\footnotetext{
${ }^{5} \mathrm{~A}$ autora alerta o leitor de que os excertos usados para as análises estão, em sua grande maioria, em inglês. A disciplina em que os dados foram coletados foi ofertada para professores de língua inglesa e, dentro da proposta curricular do curso de Letras da instituição, foi definido o idioma inglês para as interações. No entanto, alguns excertos em português também estão presentes, uma vez que as mensagens de correio, o questionário respondido pelos alunos, e a entrevista que eles concederam foram com uso da língua materna e o trabalho final da disciplina, a pedido dos alunos, teve a opção de ser redigido em língua portuguesa, também.
} 
Importante ressaltar que os excertos foram copiados do ambiente virtual onde a disciplina aconteceu e não sofreram nenhuma alteração, nem mesmo em relação à correção de erros ortográficos. Os nomes dos participantes foram trocados por razões éticas, preservando o anonimato dos professores em formação que contribuíram para este trabalho. Assim, pseudônimos foram usados no lugar dos nomes reais.

\subsection{As condições para emergência complexa}

A comunidade formada na disciplina "O uso de tecnologias digitais nas aulas de língua inglesa" consolidou-se por meio de interações entre os seus membros, gerando uma multiplicidade de eventos que provocaram reflexão, demostraram novas formas de pensar e sinalizaram mudanças de atitudes. Para permitir essa emergência de umamultiplicidade deeventos, osistemateriaqueapresentaralgumas características essenciais, que Davis e Sumara (2008) chamam de condições para a emergência complexa. Os eventos ocorridos não foram, simplesmente, provocados. Eles foram motivados pelas condições encontradas no sistema, citadas anteriormente. Cada uma dessas condições, já pré-estabelecidas por Davis e Sumara (2008), é analisada individualmente, dentro do contexto da pesquisa.

\subsubsection{Diversidade interna}

Condição associada à heterogeneidade do sistema, a diversidade interna pode ser percebida no sistema analisado nas diferentes origens de alguns alunos do curso, mesmo dentro da Licenciatura em Letras. Duas alunas, Sílvia e Aline, não eram alunas da Licenciatura em Língua Inglesa. ${ }^{6} \mathrm{O}$ uso da língua inglesa, apesar disso, não

${ }^{6}$ Sílvia cursava Licenciatura em Língua Portuguesa e Aline cursava Licenciatura em Língua Portuguesa e Italiano. 
se apresentou como um problema para Sílvia, mas mostrou-se um desafio para Aline, que se manifestou em mensagem enviada diretamente ao $e$-mail da professora.

Olá PROFESSORA, ao ver as atividades do Teleduc, senti um pouco de dificuldade e então certamente você as perceberá. Eu não sou do inglês, minha habilitação é [...],rsrsrs. (...) (ALINE, Excerto 01)

Aline participou ativamente da disciplina, sendo capaz de se comunicar na língua inglesa em todos os espaços. Em apenas um momento ela se manifestou através do correio interno do TELEDUC, em Português.

Oi PROFESSORA, peço desculpas por estar enviando esse e-mail em português, mas não sei se conseguiria me expressar adequadamente em inglês. Então, como tive dificuldade, me conectei atrasada na plataforma e perdi algumas organizações, não fui encaixada em nenhum grupo. (...) Abraços. (ALINE, Excerto 02)

Outro exemplo relevante para demonstrar a diversidade interna do sistema, segundo a autora, é o caso da aluna Inês. Ela não tem muita familiaridade com o computador e esta foi a sua primeira disciplina online, como se percebe no excerto abaixo.

[THE SUBJECT] was my first experience with online disciplines and that alone poses a difficulty to my development. (INÊS, Excerto 04)

Inês e Aline trabalharam no mesmo grupo para a realização do estágio. Em atendimento presencial realizado pela professora, na Faculdade de Letras, as duas alunas afirmaram que uma estava ajudando a outra nas suas dificuldades. 
Esta característica não foi imposta ao sistema e foi reconhecida em uma tarefa significativa, como propõem Davis e Sumara (2006, 2008). A organização do estágio e a proposta do trabalho com os alunos na escola de Ensino Fundamental foi uma tarefa articuladora, que proporcionou uma ação coletiva e fez com que as diferenças, que isoladamentepoderiamserconsideradasnegativas, proporcionassem experiências positivas. Adinâmica de trabalho de Inêse Aline garantiu interações que fizeram emergir comportamentos inovadores das duas alunas.

\subsubsection{Redundância}

A redundância, segundo Davis e Sumara (2006, 2008), é uma qualidade essencial nos sistemas complexos. Complemento da diversidade interna, ela torna possível a co-atividade complexa e, dentro de um sistema que está sempre em mudança, ela permite a adequação e coerência do sistema.

No contexto investigado, um exemplo de redundância que pode ser percebido é a língua estrangeira que todos os membros da comunidade usavam para se comunicar. Oito, dos dez alunos que participaram da pesquisa, cursavam a licenciatura em Inglês. No caso das alunas Aline e Inês, citado para ilustrar o exemplo de diversidade, é possível afirmar que a redundância pode ser reconhecida a partir da capacidade que elas tinham de uso da língua inglesa, e essa redundância exerceu os dois papeis essenciais a que Davis e Sumara (2006) se referem: ela possibilitou a interação entre os agentes e tornou possível a compensação de falhas desses mesmos agentes.

Mesmo sendo capaz de comunicar-se por escrito na língua inglesa, Aline revelou a dificuldade no uso desse idioma para a comunicação oral. As competências e as colaborações foram distribuídas, evidenciando uma capacidade de substituição do outro 
nas situações de desestabilização do sistema. A interação das duas alunas no estágio provou ter sido benéfica, como se pode inferir da fala de Inês.

[...] o medo da Aline era diferente do meu, porque a Alinejá era mais tranquila com relação à...à abordagem, né, e medo com relação à língua, porque era não era do Inglês, era do... Italiano, eu acho que era do Italiano mesmo, e...o medo dela era da aula, da língua em si, né, e o meu medo já era outra coisa, era aplicação do que a gente tava propondo, eu acho que funcionou muito bem por causa disso. (INÊS, Excerto 05)

A motivação dos alunos em relação ao curso também pode ser considerada exemplo de redundância, uma vez que o grupo demonstrou concordância na afirmação de que a busca pela disciplina se dava pelo desejo de se aperfeiçoar no uso da tecnologia no contexto educacional. A familiaridade deles com o uso do computador, o acesso à internet para comunicação e a experiência prévia em disciplinas online também podem ser acrescentados a esse grupo de exemplos.

Elemento central em torno do qual a comunidade se organizou, o interesse na aprendizagem e utilização de tecnologias na sala de aula era consenso entre o grupo, que, com exceção de Inês, já lidava com e-mail e redes sociais com frequência. Isso proporcionou o engajamento nos trabalhos, a realização das tarefas e o cumprimento do propósito do curso.

Percebeu-se que não houve risco de uma máxima redundância que pudesse reduzir a dinamicidade do sistema, diminuindo sua capacidade de responder a eventos de forma inteligente (DAVIS; SUMARA, 2006), uma vez que o grau de familiaridade dos integrantes da comunidade com o meio online variava, e alguns deles acessavam mais espaços virtuais do que outros. Dos oito alunos que responderam a esse item no questionário, apenas cinco já haviam 
cursado uma disciplina online, sendo que um deles havia cursado a disciplina em outra área de conhecimento. $O$ próprio conhecimento anterior dos membros da comunidade em relação às ferramentas do curso revelava essa variação. $O$ excerto abaixo é uma resposta a esse questionamento feito no questionário respondido pelos alunos.

Eu conhecia blogs, e também uma vez trabalhei na formação de um site, com um amigo, no qual produzíamos revistas virtuais (e-book). (SILVIA, Excerto ०6)

Foi possível perceber que os membros da comunidade analisada não estavam no mesmo patamar em termos de ambiência no meio virtual, e essas variações foram fontes de estabilidade e criatividade, uma vez que a dinâmica provocada pelas trocas de informações sobre as ferramentas facilitou o entendimento de conceitos e favoreceu reflexões significativas sobre alguns elementos do meio virtual. Experiências trocadas, dúvidas esclarecidas, reflexões geradas por comentários de um usuário mais ou menos experiente de uma ferramenta foram eventos percebidos ao longo das interações nos fóruns. As interações entre Pedro/Fábio e Pedro/Bárbara, por exemplo, são amostras dessa troca de experiências com uso das ferramentas.

My question is how much training would a teacher need to use the tool and also how much time would the teacher dispose for checking and directing the activity? I have a group of 30 students in mind, and all of them participating, posting, commenting and writing... It is a wonderful tool but I believe that the teacher must be well organized and well trained so that he does not lose control of what the students are supposed to focus on. (PEDRO, Excerto 07) 
For being a so resourceful tool, I think that Glogster activities would be better held with smaller groups. I have to confess that even I (I consider myselfvery accurate with technology) had to spend some time to deal properly with it. (FÁBIO - em resposta a PEDRO. Excerto 08)

It is a wonderful tool but I believe that the teacher must be well organized and well trained so that he does not lose control of what the students are supposed to focus on. (PEDRO, Excerto 09)

I agree with you, Pedro. The first time I used Glogster was very hard. But after you get the hang of it; it turns out to be a very enriching tool. (BÁRBARA - em resposta a PEDRO. Excerto 10)

Fábio (Excerto o8) já tinha uma vivência no uso do Glogster e a partir dessa experiência ele auxilia Pedro com sua opinião sobre o melhor contexto e organização da sala de aula para usar a ferramenta. Bárbara também dá sua opinião em resposta ao comentário de Pedro, no Excerto 10, alertando-o sobre a complexidade da ferramenta, a princípio, mas tranquilizando-o quanto ao sucesso com seu uso. Essas respostas obtidas por Pedro, dos dois colegas, provavelmente contribuíram para a confiança dele em relação à esse recurso tecnológico (Glogster) e à tomada de decisões sobre seu uso em situações futuras.

As diferenças, bem como as semelhanças, atuaram como fatores que contribuíram para uma maior assimilação de ideias, conceitos e possibilidades, e proporcionaram reflexões valiosas para esses professores em formação. 


\subsubsection{Controle descentralizado}

Uma vez que a disciplina "O uso de tecnologias digitais nas aulas de língua inglesa" foi realizada em caráter online, em um AVA, o controle foi distribuído entre as redes que se formaram ao longo do curso, seguindo a proposta de Davis e Sumara (2006). Essa distribuição do controle não acontece como uma imposição; pelo contrário, ela é uma característica que se revela em SACs, que chegam à solução de problemas por meio de ajustes e interações consecutivas.

A professora estava sempre presente, já que, segundo Martins (2008), "sua presença já está virtualmente posta no desenho instrucional do curso" (MARTINS, 2008, p. 81). As ações do grupo não eram controladas e a iniciativa de dar partida no processo de discussão era incentivada. Havia, sempre, uma indicação de compartilhamento de responsabilidades e tarefas. A professora esperava que possibilidades interpretativas pudessem surgir a partir da produção participativa iniciada pelos próprios alunos

No entanto, essa expectativa da professora em relação à iniciação das interações nos fóruns não foi correspondida. As interações eram iniciadas por ela, e isso foi reconhecido por um participante da comunidade. Isso aponta uma condição inicial do sistema, que fazia disparar o fluxo de respostas e comentários.

[...] quando a gente não mexia muito no fórum ela mesma [a professora] ia lá e fazia as perguntas. (LEANDRO, Excerto 11)

As interações a partir do questionamento inicial, no entanto, seguiam tranquilamente, sem a necessidade do controle da professora. Os alunos se organizavam na troca de ideias e passavam a levantar questionamentos que eram respondidos pelos outros colegas. O excerto abaixo demonstra uma dessas interações, que aconteceu em uma discussão sobre o uso de quadrinhos na sala de 
aula, discussão essa provocada pela análise de ferramentas online de criação desses quadrinhos.

Do you think kids respond better to comic books rather than regular books? (BÁRBARA, Excerto 12)

I believe they do. At least, most of them. Children normally don't have the necessary patience to work with regular books. (ANTONIO - Em resposta a BÁRBARA. Excerto 13)

I totally agree with you. Besides, I think people and especially teachers have been looking down on comic books a lot. (BÁRBARA - Em resposta a ANTONIO. Excerto 14)

As orientações para a realização do estágio foram especificadas no desenho do curso. A partir da formação dos grupos, no entanto, as ações de seus integrantes passaram a ser menos controladas e as equipes se mobilizaram para cumprir as tarefas necessárias.

Olá pessoal, eu fui (à escola) hoje pela manhã e conversei com uma senhora que me disse que o professor está no CP hoje à tarde e na quarta pela manhã. Eu vou lá na quarta feira novamente. (PEDRO. Excerto 15).

[...] vamos dar aulas para a turma do 9 ano às quartas pela manhã de 8 às 9:40. Nossas aulas acontecerão nos dias 01 , 08 e 15 de junho. (PEDRO, Excerto 16)

A professora acompanhou o processo do cumprimento das tarefas, atuando como uma personagem coadjuvante no sistema. Decisões do tipo "quando fazer o primeiro contato com a escola onde o estágio seria realizado", "formas de organização do grupo dentro da escola" e "a definição dos momentos do estágio" foram tomadas pelo grupo, de forma coletiva. As questões organizacionais e o cumprimento das tarefas são padrões que, segundo Braga (2007), 
se movem juntos na mesma direção e o comportamento emergente da relação entre os pares reforça o caráter complexo da comunidade aqui investigada. Nessa comunidade de professores em formação, a solução de problemas de maneira compartilhada, que demonstrou uma mobilização efetiva de competências distribuídas, favoreceu o equilíbrio do sistema. Houve uma finalidade única para as ações do grupo, que fez com que eles se organizassem e se orientassem por esse objetivo em comum. A prática de estágio realizada por eles com o grupo de alunos do Ensino Fundamental foi uma ação que emergiu dessa organização.

Pode-se dizer, então, que longe de uma dinâmica centralizadora e hierarquizada, os agentes participaram da solução de problemas e contribuíram para a dinamicidade do sistema. Essa mobilização conjunta se deu em virtude do que Lévy (1996) chama de uma inteligência distribuída e valorizada, modelada por uma energia mutuamente constante, em uma democracia em tempo real. Essa inteligência coletiva foi modelada por “regras do jogo" (LÉVY, 1996), em uma dinâmica equilibrada de normas e possibilidades, apontada na próxima subseção.

\subsubsection{Coerência e aleatoriedade - restrições possibilitadoras}

Não importa em que contexto nível social, estamos sujeitos a normas e regras que governam nosso comportamento e estruturam as ações. As normas e regras, porém, não devem ir a um extremo de controle absoluto e nem a outro extremo de liberdade exagerada. Elas devem funcionar como restrições possibilitadoras, que garantem “o equilíbrio entre as fontes de coerência, que permitem um coletivo manter o foco em um propósito, e as fontes de aleatoriedade, que levam o coletivo a ajustes e adaptações constantes" (DAVIS; SUMARA, 1996, p. 147). 
Importante esclarecer que as normas gerais que regiam a disciplina "O uso de tecnologias digitais no ensino de língua inglesa" foram estabelecidas no espaço "Dinâmica do Curso" e no arquivo denominado "Guidelines", disponibilizado no espaço "Parada Obrigatória”. Segundo ela, os alunos receberam informações sobre o prazo para postagens de resumos dos textos, o registro da frequência e a organização da turma para a realização do estágio. As formas como eles fariam o resumo, bem como as ações para a criação do projeto do estágio e a implementação do mesmo na escola de Ensino Fundamental não foram estabelecidas. Assim, tendo consciência do que era para ser feito, os alunos puderam decidir como fazer e qual a melhor forma de interação para chegar a um resultado satisfatório.

A interação dos alunos na semana destinada ao webinar (seminário online realizado por eles) aponta uma aleatoriedade no sistema. A orientação dada previa a interação dos alunos para reflexões sobre os projetos criados. Apesar de o fórum Webinar ter sido criado e ele ter sido usado por uma aluna para um questionamento à professora, os alunos recorreram ao espaço de comentários no Portfólio para dar o feedback esperado, já que os projetos criados por eles foram postados nesse espaço. A tarefa proposta foi totalmente cumprida, mas com uma variação na forma de realização, que não inviabilizou o processo. O propósito comum foi alcançado, com um ajustamento feito pelos próprios participantes.

\subsubsection{Interações locais}

Compreendendo o conhecimento como potencial de ação, sujeito a revisões constantes a partir das novas experiências integradas, Davise Sumara (2006) propõem que a ativação desse potencial pode disparar outros, que serão integrados a possibilidades mais sofisticadas. Esse argumento dos autores se exemplifica nas interações ocorridas em conferências, seminários, publicações em periódicos, conversas 
pelos corredores de escolas e outras associações, e interações mediadas por texto, que possibilitam um engajamento em um diálogo que promove uma justaposição de ideias.

Sem desconsiderar o componente físico das interações, e a autora acrescenta também o componente contextual, Davis e Sumara (2006) afirmam que o mecanismo acionado nos contextos citados anteriormente é o encontro involuntário de ideias, que garante a emergência de eventos de aprendizagem.

Considerando o grupo analisado nesta pesquisa, pode-se afirmar que as interações locais, representadas pelas leituras realizadas, pelas atividades práticas vivenciadas com uso das ferramentas e pelas discussões nos diversos espaços propostos na disciplina foram fundamentais para as dinâmicas participativas e o reconhecimento de novas possibilidades nos contextos de ensino e aprendizagem. No exemplo da aluna Inês é possível atestar que as interações entre as diferenças e semelhanças contribuíram para o surgimento de respostas a situações emergentes, e que a aprendizagem ocorreu de alguma forma. Sua fala, registrada no excerto abaixo, aponta a sua conclusão para esse fato.

[...] no dia em que eu fui fazer a apresentação do seu trabalho lá...no...(escola), eu vi que isso não importava tanto assim, não tanto quanto eu tava pensando, sabe, é...que eu entraria com a parte do Inglês e muita coisa eu sabendo fazer, o que o site tava disponibilizando, às vezes nem que eu não soubesse mexer em tudo, sempre ia ter alguém para poder chegar e dizer "ah não é assim", isso ajuda bastante...assim, deu pra perder o medo [...] (INÊS, Excerto 17)

Inêspercebeuopotencial dacolaboraçãonatarefaeconstatouque sua função, a de professora, era capaz de ser cumprida com eficiência, e que a ajuda em relação ao aparato tecnológico poderia vir de outra pessoa. De fato, na observação às aulas dadas por Inês, foi notório o 
receio inicial de que os alunos fizessem algum questionamento sobre a ferramenta e que ela não soubesse responder.7 Mesmo sabendo que teria a colaboração de Aline, ela ainda temia a exposição de sua falta de familiaridade com o meio online. Talvez, antes de vivenciar a experiência e chegar à conclusão expressa em seu comentário, Inês receasse a perda de controle da situação, a que Prensky se refere, deixando de ser "a única na sala que sabe" (PRENSKY, 2007, p. 4). De certa forma, é perceptível na fala dela o reconhecimento do que Prensky (2007) chama de "divisão útil do trabalho": os professores, especialmente aqueles que receiam a tecnologia, têm a função de trabalhar de forma reflexiva e orientadora com seus alunos, para que eles entendam como usar a tecnologia, o que elas podem oferecer, e como incluí-las na rotina de estudos; os aprendizes têm o trabalho de produzir, de criar com a ajuda do meio online, podendo servir como apoio ao professor em suas dúvidas tecnológicas, quando eles demonstrarem mais domínio da(s) ferramenta(s) utilizada(s).

Outra evidência da interação local ocorrida no grupo foi a ligação explícita entre os textos trabalhados em sala e a realização das tarefas referentes ao estágio. $O$ excerto abaixo traz um registro desse fato.

Dentre os vários textos lidos, escolhi os que foram mais relevantes na elaboração do plano de aula do nosso grupo. O primeiro deles: "Myths and realities about technology in K-12" é mais geral e fala dos mitos sobre o uso de tecnologias na sala de aula, o que é muito importante para que nos livremos dos preconceitos e do senso comum na teoria para que tenhamos uma prática mais eficiente. O segundo: "Informática no ensino fundamental: beneficios ou prejuízos?” mostra o lado negativo, ou seja, é importante vermos as afirmativas contrárias ao uso de tecnologias na sala de aula para que não invistamos em algo pensando que não teremos os contras. E o terceiro: "Exploring the Perspectives and Potential of Incorporating Glogster in the University EFL Curriculum Arab World English Journal."

${ }^{7}$ Informação retirada das notas de campo da professora pesquisadora. 
é relacionado ao uso do glogster que foi a ferramenta escolhida por nós para ser trabalhado justamente porque tivemos a evidência de uma experiência bem sucedida no artigo lido. (JÚLIA, Excerto 18)

Júlia demonstra, em registro escrito ao fim do curso, que a leitura, a releitura e possivelmente as discussões sobre os textos nos fóruns, produziram uma densidade de ideias que interagiram e fizeram emergir o plano de aula do curso. Davis e Sumara (2006) fazem referência a essa densidade de ideias como consequência do mecanismo citado no início desta seção (potencial de ação sujeito a revisões que geram outros potenciais).

A partir dos dados apresentados, que a presença dessas condições possibilita o favorecimento da especialização (no sentido de aperfeiçoamento do conhecimento sobre um assunto) que decorre da tensão entre a diversidade e as semelhanças dentro do sistema; da aprendizagem em diversos níveis, que possibilita as interações locais através do controle descentralizado; e das possibilidades que surgem através das restrições do ambiente, equilibrando coerência e aleatoriedade.

A evidência significativa da proposta reflexiva que o AVA traz em si, no processo de formação de professores, é percebida nas análises das condições de emergência apontadas nesta seção. A autora considera importante salientar que esta pesquisa, apesar de evidenciar a plataforma TELEDUC na realização da disciplina em que os dados foram coletados, estende sua avaliação a AVAs em geral, sejam eles formais (especificamente projetados para ensino e aprendizagem) ou informais (não projetados para fins educacionais). Esse espaço pode ser representado apenas por uma plataforma, ou por uma junção de plataformas, ferramentas e os diferentes recursos da web, sempre "povoado" por indivíduos em trocas, o que o constitui um espaço complexo. 


\section{Considerações finais}

As condições para a emergência complexa identificadas por Davis e Simmt (2003) e Davis e Sumara (2006) foram observadas no grupo investigado. Elas se apresentam de forma inter-relacionada e contribuem para que o sistema se mantenha estável, coerente e equilibrado. Percebeu-se, também, que o grupo se organizou de maneira que cada membro fosse igualmente responsável pelas ações e trocas ocorridas. Isso tornou possível a emergência do conhecimento em potencial, proporcionado pelo acesso aos novos discursos que os textos teóricos geravam a eles.

O senso de comunidade que o espaço virtual proporciona, aproxima os professores em formação do desenvolvimento de competências docentes e tecnológicas necessárias para a atuação pedagógica. A aprendizagem está centrada nesse espaço em que o professor em formação está inserido. Essa circunstância agrega valor ao processo de formação do professor, promove a ressignificação de crenças, suposições e valores relacionados à educação, estimula reflexões com caráter de autoavaliação, de autoanálise e de negociações de sentido individuais e coletivas.

Ela explica que isso também é possível devido ao caráter textual das relações estabelecidas na comunidade virtual. Ao registrar suas ideias, opiniões, críticas e avaliações de forma escrita, o professor em formação tem a chance de exercitar o processo de pensamento elaborado de análise e síntese. É possível concluir que a formação de professores se beneficia desse tipo de organização conectada, pois esse comportamento favorece a aprendizagem e agrega conhecimento, levando professores em formação a experimentar a elaboração de trabalhos gerados a partir do diálogo com seus pares.

Os resultados desta pesquisa, evidenciam o valor do uso pedagógico do espaço virtual como apoio no momento da prática de ensino e do estágio supervisionado, bem como na construção da 
competência tecnológica do professor em formação. A partir dos resultados deste trabalho, foi possível perceber tímidos avanços nas posturas acadêmicas (refletidas nas discussões em fóruns e trocas de informação sobre as práticas em sala de aula), nas práticas reflexivas mencionadas, nos posicionamentos diante das novas tecnologias digitais e nas ressignificações de ideias pré-concebidas sobre ensino e aprendizagem e uso das TICs. No entanto, esses avanços podem significar uma postura discursiva, apenas, que pode ou não provocar alterações em práticas futuras.

\section{Referências}

BARRETTO, E. S. S. Políticas e práticas de formação de professores da educação básica no Brasil: um panorama nacional. Revista Brasileira de Politica e Administração da Educação (RBPAE), v. 27, n. 1, p. 39-52,jan./abr. 2011.

BERTALANFFY, L. Teoria geral dos sistemas. Tradução de Francisco M. Guimarães. Petrópolis: Vozes, 2008.

BOGDAN, R. C.; BIKLEN, S. K. Qualitative research for education: An introduction to theory and methods. Boston: Allyn and Bacon, Inc, 1982.

BRAGA, J. C. F. Comunidades autônomas de aprendizagem on-line na perspectiva da complexidade. 2007. 207 f. Tese (Doutorado em Linguística Aplicada) Universidade Federal de Minas Gerais, Belo Horizonte.

CAPRA, F. A teia da vida: uma nova compreensão científica dos sistemas vivos. Tradução de Newton R. Eichemberg. São Paulo: Cultrix, 1996. 256 p.

CARVALHO, C. H. de A. Política para o ensino superior no Brasil (1995-2008). Ruptura e continuidade nas relações entre público e privado. In: SILVA, J. R. S. Jr.; OLIVEIRA, J. F.; MANCEBO, D. (orgs.). Reforma universitária: dimensões e perspectivas. Campinas: Alínea, 2006. p. 125-139. 
CILLIERS, P. Complexity and postmodernism: understanding complex systems. New York: Routledge, 1998.

CLARK, S.; MAHER, M. L. The Role of Place in Designing a Learner Centered Virtual Learning Environment. In: CAAD Futures Conference. Holanda, 2001. p. 187-200.

DAVIS, B. Complexity and Education: Vital Simultaneities. In: MASON, M. (org.). Complexity Theory and the Philosophy of Education. Malden. MA: WileyBlackwell, 2008.

DAVIS, B.; SIMMT, E. Understanding Learning Systems: Mathematics Education and Complexity Science. Journal for Research in Mathematics Education, v.34, p. 137-177, 2003.

DAVIS, B.; SUMARA, D. Complexity and Education: Inquiries into Learning, Teaching and Research. Mahwah, NJ: Lawrence Erlbaum, 2006.

DILlENBOURG, P.; SCHNEIDER, D. K.; SYNTETA, P. Virtual Learning Environments. In:DIMITRACOPOULOU, A. (ed.).Proceedings of the 3 rd Hellenic Conference "Information \& Communication Technologies in Education. Kastaniotis Editions, Greece, 2002.p.3-18.

DUFFY, T. M.; CUNNINGHAM, D. J. Constructivism: Implications for the design and delivery of instruction. In: JONASSEN, D. H. (ed.). Handbook of research for educational communications and technology. N.Y: Macmillan Library reference USA, 1996.

HANNAFIN, M. J.; HANNAFIN, K. M.; LAND, S. M.; OLIVER, K. Grounded practice and the design of constructivist learning environments. Educational Technology Research and Development, v. 45, n. 3, p. 101-117, 1997.

HAMMERSLEY, M.; ATKINSON, P. Ethnography: principles in practice. Tavistock: London. 1995.

HINE, C. Virtual Ethnography. London: SAGE Publications, 2000. 
HIXON, E.; SO, H. J. Technology's Role in Field Experiences for Preservice Teacher Training. Educational Technology \& Society, v. 12, n. 4, p. 294-304, 2009.

HOLLAND, J. H. A ordem oculta: como a adaptação gera a complexidade. Tradução de José Luís Malaquias. Lisboa: Gradiva, 1998.

KAUFFMAN, S. The Origins of Order: Self-Organization and Selection in Evolution. Oxford University Press, 1993.

KELSO, J. A. S. Dynamic patterns: The self-organization of brain and behavior. MIT Press, 1995.

KUHN, L.; WOOG, R. Vortical postmodern ethnography: Introducing a complexity approach to systemic social theorizing. Systems Research and Behavioral Science, n. 22, p. 139-150, 2005.

LAND, S. M.; HANNAFIN, M. J. Student-centered learning environments. In: JONASSEN, D. H.; LAND, S.M. Theoretical Foundations of Learning Environment. New Jersey: Lawrence Erlbaum Associates, 2000.

LARSEN-FREEMAN, D.; CAMERON, L. Complex systems and applied linguistics. Oxford: Oxford University Press, 2008.

LÉVY, P. O que é virtual? Tradução Paulo Neves. São Paulo: Editora 34 Ltda., 1996. $157 \mathrm{p}$.

LINCOLN, Y.; GUBA, E. Naturalistic inquiry. Newbury Park, CA: Sage, 1985.

MARTINS, A. C. S. A emergência de eventos complexos em aulas on-line e face-aface: uma abordagem ecológica. 2007. 189 f. Tese (Doutorado em Linguística Aplicada) - Universidade Federal de Minas Gerais, Belo Horizonte, 2007.

OSBERG, D.; BIESTA, G.; CILLIERS, P. From representation to emergence: Complexity's challenge to the epistemology of schooling. Educational Philosophy and Theory, v. 40, n. 1, p. 213-227, 2008.

PAIVA, V. L. M. O. O Novo Perfil dos Cursos de Licenciatura em Letras. In: TOMICH, et al. (orgs.). A interculturalidade no ensino de inglês. Florianópolis: UFSC, 2005. p. 345-363. 
PALAZZO, L. A. M. Complexidade, caos e auto-organização. 1999. Disponível em: http://algol.dcc.ufla.br/ monserrat/isc/Complexidade_caos_autoorganizacao. html. Acesso em: 20 mai. 2012.

PARREIRAS, V. A sala de aula digital sob a perspectiva dos sistemas complexos: uma abordagem qualitativa. 2005.356 f. Tese (Doutorado em Linguística Aplicada) - Faculdade de Letras da Universidade Federal de Minas Gerais/UFMG, Belo Horizonte, 2005.

PATTON, M. Q. Qualitative Evaluation and Research Methods. 2. ed. Newbury Park, CA: Sage Publications, Inc., 1990.

PEA, R. D.; GOMEZ, L. M. Distributed Multimedia Learning Environments: Why and How? Interactive Learning Environments, v. 2, n. 2, p. 73-109, 1992.

PRENSKY, M. How to teach with technology: Keeping both teachers and students comfortable in an era of exponential change. Emerging Technologies for Learning, v. 2, 2007. Disponível em: http://partners.becta.org.uk/page_ documents/research/emerging_technologieso7_chapter4.pdf. Acesso em: 14 mar. 2012.

SANTOS, L. C. L. O ambiente Virtual como Suporte ao Estágio Supervisionado em Biologia. In: MERCADO, Luís P. Vivências na aprendizagem na Internet. Maceió: Edufal, 2005·p. 176.

SILVA, L. O. Estágio supervisionado com uso de ambientes virtuais: possibilidades colaborativas. 2013. 193 f. Tese (Doutorado em Linguística Aplicada) Universidade Federal de Minas Gerais/UFMG, Belo Horizonte, 2013.

STRAUSS, A.; CORBIN, J. Basics of qualitative research: Grounded theory procedures and techniques. Newbury Park, CA: Sage Publications, Inc., 1990.

STRUDLER, N.; WETZEL, K. Lessons from exemplary colleges of education: Factors affecting technology integration in preservice programs. Educational Technology Research and Development, v. 47, n. 4, p. 63-81, 1999. 


\section{Como citar}

SILVA, Luciana de Oliveira. A emergência complexa nas interações de um grupo de professores em formação em ambiente virtual. Revista da Abralin, v. 18, n. 1, p. 02-39, 2019.

Recebido em 23/04/2019 e aceito em 29/05/2019 